\title{
Single Dose and Multi Dose Screening Assay of Entomopathogenic Fungi against Rice Leaf Roller, Cnaphalocrocis medinalis Guen
}

\author{
Malini Nilamudeen* and K. Sudharma \\ Department of Agriculture Entomology, College of Agriculture, Vellayani, \\ Thiruvananthapuram, Kerala, India \\ *Corresponding author
}

\begin{tabular}{|c|c|}
\hline & A B S T R A C T \\
\hline $\begin{array}{l}\text { K e y w o r d s } \\
\text { Entomopathogenic } \\
\text { fungi, Single dose } \\
\text { screening assay, } \\
\text { Multi dose } \\
\text { screening assay }\end{array}$ & \multirow{3}{*}{ 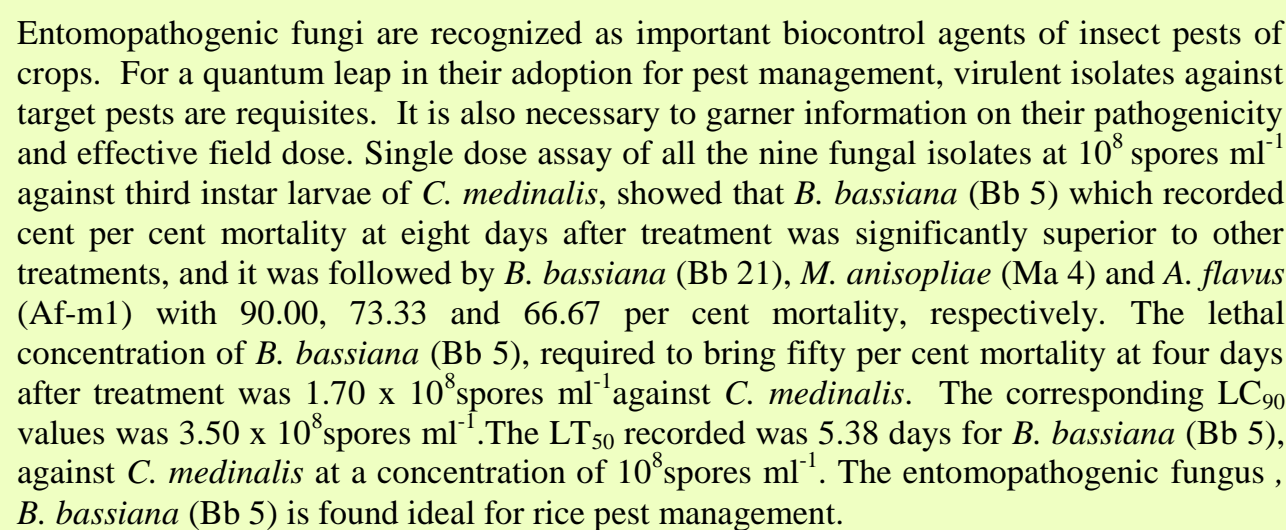 } \\
\hline Article Info & \\
\hline $\begin{array}{l}\text { Accepted: } \\
15 \text { August } 2020 \\
\text { Available Online: } \\
10 \text { September } 2020\end{array}$ & \\
\hline
\end{tabular}

\section{Introduction}

Of the different microbes, the entomopathogenic fungi having the ability to breach insect cuticle and enter insect body to cause infection in both chewing and sucking insects are considered as promising candidates in biocontrol programmes. Food security is a critical issue. In Asia, where the main caloric intake of people comes from rice, its production is also crucial. Insect pests that ravage the rice crop are one of the impediments in maximising its production. The crop is prone to the attack of the leaf roller, C. medinalis which appear in the vegetative phase as well as in the panicle initiation to booting stages cause 63 to 80 per cent yield loss. Even today, to contain them toxic insecticides are mainly depended upon. Henceforth, safer management strategies incorporating biocontrol agents are warranted in rice crop too to ward off the adversities of insecticides. As information pertaining to pathogenicity of the entomopathogenic fungi to rice pests is meager, studies are absolutely essential in this line. Temperature and relative humidity are the two physical factors having much impact on the development of fungal 
infections (Benz, 1987 and James et al., 1998). The microclimate prevailing in waterlogged paddy fields ensure high humidity and favour the use of entomopathogenic fungi for pest management in rice. The present experiment was conducted to assess the comparative efficacy of nine isolates of entomopathogenic fungi and to establish the dose mortality response of the most potent isolate identified from first experiment. Single dose assay of all the nine fungal isolates at $10^{8}$ spores $\mathrm{ml}^{-1}$ against third instar larvae of $C$. medinalis, showed that $B$. bassiana $(\mathrm{Bb} 5)$ which recorded cent per cent mortality at eight DAT was significantly superior to other treatments, and it was followed by $B$. bassiana ( $\mathrm{Bb} 21$ ), $M$. anisopliae (Ma 4) and A. flavus (Af-m1) with 90.00, 73.33 and 66.67 per cent mortality, respectively.

\section{Materials and Methods}

\section{Single dose screening assay}

For comparing the pathogenicity of the fungal isolates, Beauveria bassiana (Balsamo) Vuillemin (Bb 5 -NBAII isolate and $\mathrm{Bb} 21$ KAU isolate), Metarhizium anisopliae (Metschnikoff) Sorokin (Ma 4- NBAII isolate) and the indigenous fungi viz., Aspergillus flavus Link. (Af-m1), B. bassiana (Bb-m2, Bb-m3, Bb-m4 and Bb-m5) and $M$. anisopliae (Ma-m1) at a single dose, against major rice pest $C$. medinalis an experiment was carried out in completely randomised design (CRD) with three replications, each replication having 10 insects. The spore concentration used against third instar larvae of $C$. medinalis was $10^{8}$ spores $\mathrm{ml}^{-1-1}$ based on the preliminary trials conducted. Application of spore suspension and assessment of pathogenicity was done as mentioned above. The treated insects were observed daily until per cent mortality was observed in any one of the treatments. Percentage mortality was corrected using Abbot's formula (Abbot, 1925 ) and the angular transformed values were statistically analysed using ANOVA.

\section{Preparation of Spore Suspension}

The spore suspensions were prepared aseptically by pouring $10 \mathrm{ml}$ of sterile water into 14 day old culture of all test fungi except A. flavus, for which seven day old culture was used. $10 \mathrm{ml}$ spore suspension thus obtained from each Petri plate was made up to $30 \mathrm{ml}$ and applied topically on the test insects using an atomizer for assessing pathogenicity.

\section{Pathogenicity test}

\section{Larvae}

The third instar larvae collected from the stock culture were kept in refrigerator for two min to reduce their activity. Larvae sprayed with water served as untreated check. After one $\mathrm{h}$, the treated / untreated larvae were transferred to rice plants kept in $250 \mathrm{ml}$ conical flasks containing water and the mouth of the flask were covered with cotton. The larvae were confined to these plants with perforated polythene covers, free end of which was tied to the neck of the conical flasks. The larvae were observed for symptom development for two weeks.

\section{Multi dose screening assay of $B$. bassiana (Bb 5)}

Bioassay experiments were carried out to fix the lethal concentrations $\mathrm{LC}_{50}, \mathrm{LC}_{90}$ and $\mathrm{LT}_{50}$ of the most potent isolate identified from single dose screening assay, i.e, B. bassiana (Bb 5). This will establish the dose-mortality response. Fungal cultures were maintained in PDB. Spore suspensions were prepared by blending the respective fungal cultures in a mixer for $30 \mathrm{sec}$ and then sieving through muslin cloth. Neubauer's haemocytometer 
was used for determining the spore concentrations. The spore suspensions were then serially diluted to get five different concentrations of the fungi i.e., $10^{8}, 10^{7}, 10^{6}$, $10^{5}$ and $10^{4}$ spores $\mathrm{ml}^{-1}$ for evaluation against third instar larvae of $C$. medinalis. The spore suspension was applied on test insects as mentioned above. The experiments were laid out in CRD with three replications and an untreated check. In each replication, 10 test insects were used. The symptoms and mortality of test insects were recorded daily and the percentage mortality was worked out after making necessary corrections using Abbott's formula (Abbott, 1925). SPSS (Version 16.0) was used to analyse the dosemortality relationships and $\mathrm{LC}_{50}, \mathrm{LC}_{90}$ and $\mathrm{LT}_{50}$ were determined. Fiducial limits and other regression parameters were also worked out.

\section{Results and Discussion}

\section{Single dose screening assay}

The data on the mortality of the larvae of $C$. medinalis treated with different fungi, at a spore concentration of $10^{8}$ spores $\mathrm{ml}^{-1}$ are presented in Table 1.

Four days after treatment, both $B$. bassiana (Bb 5) and B. bassiana (Bb 21) caused mean mortality to the tune of 33.33 per cent which was on par with that of $M$. anisopliae (Ma 4) (26.67 per cent) and A. flavus (Af-m1)(16.67 per cent). The isolates Bb-m2, Bb-m3, Bb-m4 and Ma-m1 caused mean mortality ranging from 3.33 per cent to 10.00 per cent and were on par. The isolate Bb-m5 did not cause any mortality.

B. bassiana ( $\mathrm{Bb} 5$ ) caused 76.67 per cent mean mortality on the sixth DAT and was statistically on par with that of $B$. bassiana (Bb 21) (73.33 per cent). M. anisopliae (Ma4) produced mean mortality of 50 per cent, which was statistically superior to that of $A$. flavus (Af-m1) (30.00 per cent). The isolate Bb-m2 produced 20.00 per cent mean mortality and was statistically on par with the mean mortality by Bb-m3 and Ma-m1 (16.67 per cent) each. The indigenous isolates Bb-m4 and Bb-m5 collected from soil caused only 6.67 per cent mortality.

On the eighth DAT, cent per cent mean mortality achieved by $B$. bassiana $(\mathrm{Bb} 5)$ was statistically superior to all other isolates. This was followed by $B$. bassiana (Bb 21) with 90.00 per cent mortality. M. anisopliae (Ma 4) (73.33 per cent) and A. flavus (Af-m1) (66.67 per cent) were statistically on par. The isolate, Bb-m3 which caused 33.33 per cent mean mortality was on par with Bb-m2 (30.00 per cent) and Ma-m1 (23.33 per cent). The performance of $\mathrm{Bb}-\mathrm{m} 4$ and $\mathrm{Bb}-\mathrm{m} 5$ was inferior and caused only 16.67 and 13.33 per cent mortality, respectively. From the observations taken at different intervals after treatment, it was seen that B. bassiana (Bb 5) was the most virulent isolate.

\section{Multi dose screening assay of $B$. bassiana (Bb 5)}

The mortality of larvae of $C$. medinalis treated with the spore concentrations, $10^{4}$ to $10^{8}$ spores $\mathrm{ml}^{-1}$ of $B$. bassiana (Bb 5) ranged from 5.00 to 30.00 per cent at four DAT, (Table 2). At six and eight DAT, at the same concentrations, the mortality ranged from 10.00 to 52.50 and 12.50 to 92.50 per cent, respectively. Ten days after treatment, cent per cent mortality was observed at the highest concentration of $10^{8}$ spores $\mathrm{ml}^{-1}$. The minimum time required to bring about fifty per cent mortality at a concentration of $10^{8}$ spores $\mathrm{ml}^{-1}$ was 5.38 days. As the concentration reduced to $10^{7}, 10^{6}, 10^{5}$, and $10^{4}$, the $\mathrm{LT}_{50}$ recorded were $6.80,8.21,9.15$ and 13.27 days, respectively. 
As spore concentration varied, the mortality also varied. To bring about fifty per cent mortality at four DAT, a spore concentration of $1.70 \times 10^{8}$ spores $\mathrm{ml}^{-1}$ was required whereas concentration of $0.87 \times 10^{8}, 0.20 \mathrm{x}$ $10^{8}$ and $0.002 \times 10^{8}$ spores $\mathrm{ml}^{-1}$ were sufficient to bring about fifty per cent mortality at sixth, eighth and tenth DAT. The $\mathrm{LC}_{90}$ values at four, six, eight and ten DAT were $3.50 \times 10^{8}$, $2.59 \times 10^{8}, 0.86 \times 10^{8}$ and $0.10 \times 10^{8}$ spores $\mathrm{ml}^{-1}$, respectively.

A comparison of the pathogenicity of the fungi, assessed at a spore concentration of $10^{8}$ spores $\mathrm{ml}^{-1}$ against larvae of $C$. medinalis showed that the pathogenicity of the different fungi varied significantly, the mortality ranged from 13.33 to cent per cent against larvae of $C$. medinalis. Superior performance of the NBAII isolates of B. bassiana (Bb 5), $M$. anisopliae ( $\mathrm{Ma} \mathrm{4)}$ and the indigenous isolates, B. bassiana (Bb 21) and A. flavus (Af-m1) were noted compared to the newly collected indigenous isolates of $B$. bassiana (Bb-m2, Bb-m3, Bb-m4 and Bb-m5) and $M$. anisopliae (Ma-m1) from soil. This was evident from the mortality rates, from the initial observations and over the time exhibited in the larvae of $C$. medinalis.

Table.1 Pathogenicity of fungal isolates to third instar larvae of $C$. medinalis

\begin{tabular}{|c|c|c|c|}
\hline \multirow[t]{2}{*}{ Treatments@ $10^{8}$ spores $\mathrm{ml}^{-1}$} & \multicolumn{3}{|c|}{ Mean mortality (\%) at different DAT } \\
\hline & 4 & 6 & 8 \\
\hline B. bassiana (Bb 5) & $\begin{array}{c}33.33 \\
(35.01)\end{array}$ & $\begin{array}{c}76.67 \\
(61.22)\end{array}$ & $\begin{array}{l}100.00 \\
(89.09)\end{array}$ \\
\hline B. bassiana (Bb 21) & $\begin{array}{c}33.33 \\
(35.01)\end{array}$ & $\begin{array}{c}73.33 \\
(59.00)\end{array}$ & $\begin{array}{c}90.00 \\
(74.70)\end{array}$ \\
\hline M. anisopliae (Ma 4) & $\begin{array}{c}26.67 \\
(30.99)\end{array}$ & $\begin{array}{c}50.00 \\
(45.00)\end{array}$ & $\begin{array}{c}73.33 \\
(59.00)\end{array}$ \\
\hline A. flavus(Af-m1) & $\begin{array}{c}16.67 \\
(23.86)\end{array}$ & $\begin{array}{c}30.00 \\
(33.21)\end{array}$ & $\begin{array}{c}66.67 \\
(54.78)\end{array}$ \\
\hline B. bassiana (Bb-m2) & $\begin{array}{c}10.00 \\
(18.44)\end{array}$ & $\begin{array}{c}20.00 \\
(26.57)\end{array}$ & $\begin{array}{c}30.00 \\
(33.21)\end{array}$ \\
\hline B. bassiana (Bb-m3) & $\begin{array}{c}6.67 \\
(12.59)\end{array}$ & $\begin{array}{c}16.67 \\
(23.86)\end{array}$ & $\begin{array}{c}33.33 \\
(35.22)\end{array}$ \\
\hline B. bassiana (Bb-m4) & $\begin{array}{c}3.33 \\
(6.75)\end{array}$ & $\begin{array}{c}6.67 \\
(12.59)\end{array}$ & $\begin{array}{c}16.67 \\
(23.86)\end{array}$ \\
\hline B. bassiana (Bb-m5) & $\begin{array}{c}0.00 \\
(0.91)\end{array}$ & $\begin{array}{c}6.67 \\
(12.59)\end{array}$ & $\begin{array}{c}13.33 \\
(21.15)\end{array}$ \\
\hline M. anisopliae(Ma-m1) & $\begin{array}{c}3.33 \\
(6.75)\end{array}$ & $\begin{array}{c}16.67 \\
(23.86)\end{array}$ & $\begin{array}{c}23.33 \\
(28.29)\end{array}$ \\
\hline CD (0.05) & $(12.142)$ & $(9.541)$ & (7.136) \\
\hline
\end{tabular}

Mean of three replications

10 insects replication $^{-1}$

Figures in parentheses are angular transformed values.

DAT- Days after treatment 
Table.2 Dose-mortality responses of third instar larvae of $C$. medinalis treated with $B$. bassiana $(\mathrm{Bb} 5)$

\begin{tabular}{|c|c|c|c|c|c|c|c|c|c|c|}
\hline \multirow{2}{*}{\multicolumn{2}{|c|}{$\begin{array}{l}\text { Concentration } \\
\left(\text { spores } \mathrm{ml}^{-1}\right)\end{array}$}} & \multicolumn{8}{|c|}{$\begin{array}{l}\text { Cumulative per cent mortality at different days after } \\
\text { treatment }\end{array}$} & \multirow[t]{2}{*}{$\mathbf{L T}_{50}$ (days) } \\
\hline & & \multicolumn{2}{|c|}{4} & \multicolumn{2}{|c|}{6} & \multicolumn{2}{|c|}{8} & \multicolumn{2}{|c|}{10} & \\
\hline \multicolumn{2}{|l|}{$10^{8}$} & \multicolumn{2}{|c|}{30.00} & \multicolumn{2}{|c|}{52.50} & \multicolumn{2}{|c|}{92.50} & \multicolumn{2}{|c|}{100.00} & 5.38 \\
\hline \multicolumn{2}{|l|}{$10^{7}$} & \multicolumn{2}{|c|}{20.00} & \multicolumn{2}{|c|}{40.00} & \multicolumn{2}{|c|}{60.00} & \multicolumn{2}{|c|}{87.50} & 6.80 \\
\hline \multicolumn{2}{|l|}{$10^{6}$} & \multicolumn{2}{|c|}{12.50} & \multicolumn{2}{|c|}{37.50} & \multicolumn{2}{|c|}{40.00} & \multicolumn{2}{|c|}{70.00} & 8.21 \\
\hline \multicolumn{2}{|l|}{$10^{5}$} & \multicolumn{2}{|c|}{10.00} & \multicolumn{2}{|c|}{20.00} & \multicolumn{2}{|c|}{37.50} & \multicolumn{2}{|c|}{60.00} & 9.15 \\
\hline $10^{4}$ & & & & & & & .50 & 30 & & 13.27 \\
\hline \multicolumn{11}{|c|}{ Probit analysis } \\
\hline DAT & \multicolumn{2}{|c|}{$\begin{array}{c}\mathrm{LC}_{50}\left(10^{8}\right. \\
\left.\text { spores } \mathrm{ml}^{-1}\right)\end{array}$} & \multicolumn{2}{|c|}{$\begin{array}{l}\text { Fiducial limit } \\
\text { for } L C_{50}\left(10^{8}\right. \\
\left.\text { spores } \mathrm{ml}^{-1}\right)\end{array}$} & \multicolumn{2}{|c|}{$\begin{array}{c}\mathrm{LC}_{90}\left(10^{8}\right. \\
\left.\text { spores } \mathrm{ml}^{-1}\right)\end{array}$} & \multicolumn{2}{|c|}{$\begin{array}{l}\text { Fiducial limit } \\
\text { for } \mathrm{LC}_{90}\left(10^{8}\right. \\
\left.\text { spores } \mathrm{ml}^{-1}\right)\end{array}$} & $\mathrm{X}^{2}$ & Regression \\
\hline 4 & \multicolumn{2}{|c|}{1.70} & \multicolumn{2}{|c|}{$1.53-1.88$} & \multicolumn{2}{|c|}{3.50} & \multicolumn{2}{|c|}{$3.16-3.59$} & 3.629 & $Y=1.213+0.134 x$ \\
\hline 6 & & & & & & & & & 11.387 & $\mathrm{Y}=0.648+0.110 \mathrm{x}$ \\
\hline 8 & & & & & & & & & 14.559 & $\mathrm{Y}=0.387+0.105 \mathrm{x}$ \\
\hline 10 & & & & & & & & & 11.625 & $\mathrm{Y}=0.028+0.119 \mathrm{x}$ \\
\hline
\end{tabular}

The mortality of $C$. medinalis larvae ranged from 33.33 to cent per cent in B. bassiana $(\mathrm{Bb}$ 5) and it was followed by 33.33 to 90.00 per cent in $B$. bassiana ( $\mathrm{Bb} 21)$. The new indigenous isolates of $B$. bassiana from soil produced only 3.33to 33.33 percentage mortality in larvae of $C$. medinalis. The indigenous soil isolate of M. anisopliae (Ma$\mathrm{m} 1$ ) caused mortality of only 3.33 to 23.33 per cent in larvae of $C$. medinalis. From the cumulative percentage mortality it was seen that $B$. bassiana $(\mathrm{Bb} 5)$ was the most effective one against $C$. medinalis larva. In the present study, since a single dose was used for evaluating the pathogenicity of the isolates, it can be concluded that the enhanced performance of the NBAII isolates $B$. bassiana ( $\mathrm{Bb} 5$ ) and M. anisopliae (Ma 4) is due to the inherent character of the isolates. Lokesh (2014) opined that the pathogenicity of fungi varied with pests. In the studies conducted by Carneiro et al., (2008) and Sivasundaram et al., (2008), the variations in pathogenicity of the isolates of $B$. bassiana was seen from zero to cent per cent and from
26.67 to 73.33 per cent when evaluated against the fall army worm, Spodoptera frugiperda Smith and against $C$. medinalis, respectively.

The present research results are also supported by the findings of Lopes et al., (2013) who reported low pathogenicity of indigenous isolates of $B$. bassiana and $M$. anisopliae, in the adults of Cosmopolites sordidus Germ. The results necessitate the selection of the right pathogen for effective pest management. According to Butt et al., (2001), dose-mortality studies determine the minimum amount of inoculum required to cause disease in the test insect and also indicate the time the bioagents will take to have an impact on the target organisms. An overview of the bioassay results in the present study revealed a concentration dependent mortality of the test insect. At higher spore concentrations higher mortality was achieved. This trend in mortality was exhibited by the fungus tested against the larvae of $C$. medinalis. Dhuyo and Soomro (2008) 
observed dose dependent mortality of larva of Scirpophaga incertulas (Walker) when treated with B. bassiana. Similarly, Herlinda et al., (2008) recorded higher mortality in nymphs of rice bug, Leptocoris aoratorius F. with increase in concentrations of spores of both $B$. bassiana and $M$. anisopliae. From the studies of Sivasundaram et al., (2008) also, a concentration dependent mortality was seen, the mortality of $C$. medinalis reported being 26.67 and 76.67 per cent at $10^{2}$ and $10^{8}$ spores $\mathrm{ml}^{-1}$ of $B$. bassiana, respectively. The results of bioassay studies conducted by Anis (2014) against coleopteran pests and Lokesh (2014) against sucking pests of chilli are in corroboration with the present findings. The concentrations required for the pathogens, varied from $1.02 \times 10^{8}$ to $1.70 \times 10^{8}$ spores $\mathrm{ml}^{-1}$ to bring fifty per cent mortality in the third instar larvae of $C$. medinalis within the shortest period of four days.

The studies conducted by Ambethgar et al., (2007) also revealed that the dose required to bring fifty per cent mortality to the third instar larvae of $C$. medinalis varied with fungal isolates. The $\mathrm{LC}_{50}$ for the $B$. bassiana isolate, BbCmKKL1100 was observed as $2.80 \mathrm{x}$ $10^{3}$ spores $\mathrm{ml}^{-1}$ in their studies. Sivasundaram et al., (2008) further recorded $3.40 \mathrm{x}$ $10^{4}$ spores $\mathrm{ml}^{-1}$ as the $\mathrm{LC}_{50}$ value of $B$. bassiana (B2) against $C$. medinalis larvae, which were lower, in comparison with the $\mathrm{LC}_{50}$ noted in the present study, this variations can be attributed to the differences in the virulence of the isolates. Kirubakaran et al., (2013) reported $\mathrm{LC}_{50}$ value of B. bassiana MTCC7690 and M. anisopliae MTCC4104 as $9.09 \times 10^{4}$ and $6.08 \times 10^{5}$ spores $\mathrm{ml}^{-1}$ against C. medinalis larvae.

\section{Acknowledgment}

Authors are thankful to the UGC for awarding the Maulana Azad National Fellowship and KAU for providing the financial assistance for conducting the research.

\section{References}

Aizawa, K. 1987. Recent development in the utilization of microbial insecticides in Japan. Food and Fertilizer Technology, Republic of China, Taiwan, pp. 6-10.

Ambethgar, V., Swamiappan, M., Rabindra, R.J and Rabindran, R. 2007. Pathogenicity of certain indigenous isolates of entomopathogenic fungi against rice leaf folder, Cnaphalocrocis medinalis Guen. J. Biol. Control. 21 (2): 223-224.

Anis, J.R. 2014. Evaluation of entomopathogenic fungi for the management of major coleopteran pests and characterisation of pesticide tolerant strains. Ph. D thesis, Kerala Agricultural University, Thrissur, 335p.

Benz, G. 1987. Environment. In: Fuxa, J. R and Tanada, Y. (eds), Epizootiology of Insect Diseases. Wiley, New York, pp. 177214.

Blanford, S., and Thomas, M. B. 2001. Adult survival, maturation, and reproduction of the desert locust Schistocerca gregaria infected with the fungus Metarhizium anisopliae var acridum. J. Invertebr. Pathol. 78(1): 1-8.

Butt, T.M., Jackson, C.W. and Murugan, W. 2001. Fungi as Biocontrol Agents, Progress, Problems and Potentials. CBBS Publishing Co, UK, pp. 240-242.

Carneiro, A.A., Gomes, E.A., Guimaraes, C.T., Fernandes, F.T., Carneiro, N.P., and Cruz, I. 2008. Molecular characterization and pathogenicity of isolates of Beauveria spp. to fall armyworm. Brasília 43 (4): 513-520.

Dhuyo, A.R., and Soomro, N.M. 2008. Pathogenicity of Beauveria bassiana (Deuteromycota: Hyphomycetes) against the yellow stem borer, Scirpophaga incertulas (Lepidoptera: Pyralidae) under laboratory conditions. Pak. Entomol. 30: 37-42.

Fuxa, J. R., and Tanada, Y. 1987. Biological control strategies for suppression of termites. J. Agric. Entomol. 14: 281-289. 
Gul, H.T., Saeed, S., and Khan, F.Z.A. 2014. Entomopathogenic fungi as effective insect pest management tactic: a review. Appl.Sci. Bus. Econ. 1(1): 10-18.

Hemasree, E. 2013. A critical review on the natural occurrence of entomopathogenic fungi in agricultural ecosystem. Int. J. Appl. Biol. and Pharma. Technol. 372.

Herlinda, S., Mulyati, S.I., and Suwandi. 2008. Selection of isolates of entomopathogenic fungi and the bioefficacy of their liquid production against Leptocoris aoratorius nymphs. Microbiol. 2 (3): 141-146.

Ignoffo, C.M., and Garcia, C. 1985. Host spectrum and relative virulence of an Ecuadoran and a Mississippian biotypes of Nomuraearileyi. J. Invertebr. Pathol. 45: 346-352.

James, R.R., Croft, B.A., Shaffer, B.T., and Lighthart, B. 1998. Impact of temperature and humidity on hostpathogen interactions between Beauveria bassiana and a coccinellid. Environ. Entomol. 27(6): 1.506-1.513.

Kirubakaran, S.A., Narayanan, S.S., Revathi, K., Chandrasekaran, R., and Senthil, S.N. 2013. Effect of oilformulated Metarhiziumanisopliae and Beauveria bassiana against the rice leaffolder Cnaphalocrocis medinalis Guenée (Lepidoptera: Pyralidae). Arch. Phytopatho. Plant Prot. 47(8):190-191.

Lokesh, S. 2014. Evaluation of entomopathogenic fungi against pest complex of chilli (Capsicum annuum
L.). M.Sc. (Ag) thesis, Kerala Agricultural University, Thrissur, 161p.

Lopes, R.B., Mesquita, A.L.M., Tigano, M.S., Souza, D.A., Martins, I., and Faria, M. 2013. Diversity of indigenous Beauveria and Metarhizium spp. in a commercial banana field and their virulence toward Cosmopolites sordidus (Coleoptera: Curculionidae). Fungal Ecol. 6: 356364.

Pasaru,F., Anshary,A., Kuswinanti,T., Mahfudz and Shahabuddin. 2014. Prospective of entomopathogenic fungi associated with Helopeltis spp. (Hemipter: Miridae) on cacao. Int.J.Curr.Res.Aca.Rev. 2(11): 227-234. Noma and Strickler, 2000.

Rayati, D.J., and Widayat, W. 1996. Promising entomopathogenic fungi for biological control of tea and cinchona pests: their pathogenicity and some critical aspects of the disease induction, Proceedings of the Symposium on IPM Control Component, SeameoBiotrop, Bogor, Indonesia, pp. 167-174.

Shahid, A.A., Rao, A.Q., Bakhsh, A., and Husnain, T. 2012. Entomopathogenic fungi as biological controllers: New insights into their virulence and pathogenicity. Biol. Sci. 64 (1): 21-42.

Sivasundaram, V., Rajendran, L., Muthumeena, K., Suresh, S., Raguchander, T., and Samiyappan, R. 2008. Effect of talcformulated entomopathogenic fungus Beauveria against leaf folder (Cnaphalocrocis medinalis) in rice. World J. Microbiol. Biotechnol. 24: 1123-1132.

\section{How to cite this article:}

Malini Nilamudeen and Sudharma, K. 2020. Single Dose and Multi Dose Screening Assay of Entomopathogenic Fungi against Rice Leaf Roller, Cnaphalocrocis medinalis Guen. Int.J.Curr.Microbiol.App.Sci. 9(09): 1867-1873. doi: https://doi.org/10.20546/ijcmas.2020.909.235 